\title{
Impact of preozonation on the performance of coagulated flocs
}

\author{
Tao $\mathrm{Li}^{\mathrm{a}}$, Xiaomin Yan ${ }^{\mathrm{a}}$, Dongsheng Wang ${ }^{\mathrm{a}, *}$, Fulin Wang ${ }^{\mathrm{b}}$ \\ a State Key Laboratory of Environmental Aquatic Chemistry, Research Center for Eco-Environmental Sciences, Chinese Academy of Sciences, Beijing 100085, PR China \\ ${ }^{\mathrm{b}}$ Department of Civil and Environmental Engineering, Michigan State University, East Lansing, MI 48824, USA
}

\section{A R T I C L E I N F O}

\section{Article history:}

Received 12 September 2008

Received in revised form 8 December 2008

Accepted 8 December 2008

Available online 20 January 2009

\section{Keywords:}

Zeta potential

Fractal dimension

Size

Polarity

Effective density

\begin{abstract}
A B S T R A C T
Ozone have been widely used as pre-oxidant before conventional water treatment processes, while some controversial results on the effects of preozonation on coagulation and particle stabilization, have been described. The performance of coagulated flocs can be substantially influenced by preozonation which can be ascribed to the variation of particles or organic substances in water. In order to elucidate the effects of preozonation as an aid in subsequent coagulation, the synthetic water composed of kaolin suspension and humic acid was coagulated after preozonation. The properties of floc, such as, size, fractal dimension and effective density, were investigated using laser light scattering analyzer and settling column measurement. It was found that the suspended particles had not been destabilized by preozonation as regarding the slight variation of zeta potential. As the ozone dose was less than $0.53 \mathrm{mg} \mathrm{O}_{3} \mathrm{mg}^{-1} \mathrm{C}$, floc size was not influenced apparently, while, as the ozone dose increased, the flocs were broken and the size decreased remarkably. Specifically, the fractal dimensions of flocs increased with increasing ozone dose, resulting in more densely packed flocs with low branch structure. Additionally, in terms of settling characteristics, the optimal pre-ozone dose was found to be $0.53 \mathrm{mg} \mathrm{O}_{3} \mathrm{mg}^{-1} \mathrm{C}$, which led to highest effective density of flocs with best liquid-solid separation efficiency.
\end{abstract}

(c) 2009 Elsevier Ltd. All rights reserved.

\section{Introduction}

Ozone has been proved to play an important role in water and wastewater treatment as a disinfectant and oxidant (Grasso and Weber, 1988). Regarding the risks from disinfection byproducts (DBPs), preozonation has been utilized to control DBPs, as well as removing algae, taste, odors, color and viruses. Also, preozonation has been demonstrated to be an aid in coagulation for decreasing coagulant dosage, destabilizing the aggregation of particles and increasing the length of filter runs (Jekel, 1983; Farvardin and Collins, 1989).

Although preozonation has comprehensive influence on conventional water treatment processes, some controversial results on the effects of preozonation on coagulation and particle stabilization, have been described (Jekel, 1983; Felix-Filho, 1985; Grasso and Weber, 1988; Edwards and Benjamin, 1992a; Camel and Bermond, 1998; Schneider and Tobiason, 2000; Von Gunten, 2003; Yan et al., 2007). Felix-Filho (1985) considered that ozonation had no remarkable effect on the colloidal behavior of humicstabilized particles without divalent metal ions. Additionally, particle size shifted from smaller particles to larger particles with ozonation had been reported (Jekel, 1983). However, other studies

\footnotetext{
* Corresponding author. Tel./fax: +86 1062849138 .

E-mail address: wgds@rcees.ac.cn (D. Wang).
}

had also reported the paradoxical conclusion (Felix-Filho, 1985; Yan et al., 2007).

Due to the complexity of both ozone reaction chemistry and composition of experimental water, the various impacts on coagulation or liquid-solid separation by preozonation had been indicated at different ozone dosage. Reckhow et al. (1986) summarized that low ozone doses (less than $3 \mathrm{mg} \mathrm{L}^{-1}$ ) were most effective in destabilizing particle suspension, while coagulation was deteriorated with excessive dosage. Kuhn et al. (1978) found that the turbidity increased remarkably at $0.7 \mathrm{mg} \mathrm{O}_{3} \mathrm{mg}^{-1} \mathrm{C}$ and then decreased at $2.5 \mathrm{mg} \mathrm{O}_{3} \mathrm{mg}^{-1} \mathrm{C}$, when ozonating the suspension of $100 \mathrm{mg} \mathrm{L}^{-1}$ kaolinite with 5 or $10 \mathrm{mg} \mathrm{L}^{-1}$ humics. Chang and Singer (1991) found the optimal ozone-induced particle destabilization occurred with ozone dose of about $0.4-0.8 \mathrm{mg}$ $\mathrm{O}_{3} \mathrm{mg}^{-1} \mathrm{C}$. Grasso and Weber (1988) showed that the maximum suspended particles removal occurred by speculative ozone-induced flocculation at a dose of $1.5 \mathrm{mg} \mathrm{O}_{3} \mathrm{mg}^{-1} \mathrm{C}$. Additionally, Liu et al. (2007) found ozone improved turbidity removal by polyaluminum chloride at dose of $0.36 \mathrm{mg} \mathrm{O}_{3} \mathrm{mg}^{-1} \mathrm{C}$. Generally, in most cases, the dose of preozonation used in conventional water treatment practice was less than $1 \mathrm{mg} \mathrm{O}_{3} \mathrm{mg}^{-1} \mathrm{C}$, and thus only slight reduction in dissolved organic matters will be achieved. Nevertheless, preozonation can influence the characteristics of organic matters (Amy et al., 1988; Grasso and Weber, 1988; Chang and Singer, 1991; Edwards and Benjamin, 1992b). 
Despite much attention has been paid to the characteristics of natural organic matter after preozonation, such as, polarity and molecular weight distribution of organic substances (Grasso and Weber, 1988), surface charge (Edwards and Benjamin, 1992a) and size distribution of particles (Jekel, 1983), there is limited information available about the effect of preozonation on the floc properties, such as, structure, morphology and density. Therefore, in order to understand floc behaviors after preozonation comprehensively, floc properties should be investigated.

Flocs are usually not spherical and can be considered as irregular fractal aggregates in many investigations (Jiang and Logan, 1991; Gregory, 1997; Waite, 1999; Chakraborti et al., 2002; Wu et al., 2002; Jarvis et al., 2005a; Li et al., 2006). It has been demonstrated that the flocs properties, such as density and settling velocity, are non-integral functions of size, but exhibit the fractal nature with fractional power. Meanwhile, the most important characteristics of fractal flocs are self-similar and scale invariant (Jiang and Logan, 1991; Johnson et al., 1996; Gregory, 1997). Therefore, fractal theory can be employed to describe the structure and behaviors of flocs (Lee et al., 2002).

Fractal dimensions $\left(D_{f}\right)$ can be described as one of the significant properties of fractal flocs. The essentially useful feature of fractal geometry is the recognition of scale invariance as a measure to characterize structures. For a floc, the relationship between mass $(M)$ and size $(L)$ is

$M \propto L^{D_{f}}$

Normally, $D_{f}$ is usually an integer for Euclidean objects (Waite, 1999), but for fractal objects, the values of $D_{f}$ are non-Euclidean dimensionality with a value between 1 and 3 in three-dimensional space (Bushell et al., 2002). Compact flocs have a higher $D_{f}$, while aggregates with loose structures have a lower $D_{f}$. Experimental measurement of $D_{f}$ of flocs is not straightforward, and the methods available are indirect. At present, three common techniques for $D_{f}$ measurement have been developed, i.e. light scattering, settling and image analysis (Koen and Willy, 1997; Tang et al., 2002; Wu et al., 2002; Chakraborti et al., 2003).

The main objective of this investigation was to explore the performance of fractal flocs impacted by preozonation and to understand the settling behaviors of these flocs. Meanwhile, the effects of preozonation as an aid on conventional coagulation and the determination of optimal ozone dose was elucidated, based on the $D_{f}$, size and settling behavior of the coagulated flocs.

\section{Methods and materials}

\subsection{Water preparation}

Kaolin was used as simulative suspended particles. The stock suspension of kaolin was prepared in deionized water, which was similar to that described by Yukselen and Gregory (2004). The average size of the particles in suspension was close to 3-5 $\mu \mathrm{m}$ (Mastersizer 2000, Malvern, UK). Synthetic water was prepared by adding the pre-dispersed kaolin stock suspension and commercial humic acids (Tianjin Chemical, China), which was pre-dissolved in $0.1 \mathrm{M} \mathrm{NaOH}$, to the water sample constituting half deionized water as well as half tap water. Simultaneously, $0.1 \mathrm{M} \mathrm{HCl}$ was used to adjust the solution $\mathrm{pH}$ to $7.50 \pm 0.05$. After that, the synthetic water was allowed to equilibrate for $24 \mathrm{~h}$ at $20^{\circ} \mathrm{C}$. Finally, the TOC and turbidity was about $5.0 \mathrm{mg} \mathrm{L}^{-1}$ (Phoenix8000, Tekmar-Dohrmann, USA) and 8.8 NTU (Turbidimeter $2100 \mathrm{~N}$, Hach, USA), respectively. The hardness was approximately $70 \mathrm{mg}$ as $\mathrm{CaCO}_{3} \mathrm{~L}^{-1}$.

\subsection{Preozonation}

In the preozonation test, ozone provided by a laboratory generator (Ozonizer, OS-IN, Mitsubishi Electric, Japan) was added to $2 \mathrm{~L}$ synthetic water in a glass reactor, and different ozone dose was achieved by controlling the gas flow rate and adjusting the power input to the generator. Ozone dose was determined by the distinction between input and off gas and measured by iodometric method (APHA, 1995). Three applied ozone dosages were typically obtained: $0.63,2.64,4.60 \mathrm{mg} \mathrm{L}^{-1}$, which corresponded to 0.13 , $0.53,0.92 \mathrm{mg} \mathrm{O}_{3} \mathrm{mg}^{-1} \mathrm{C}$, respectively.

\subsection{Jar test}

Each $2 \mathrm{~L}$ water sample after preozonation was used for a modified jar test with continuous measurement of floc aggregation using a laser diffraction instrument (Mastersizer 2000, Malvern, UK). Coagulation experiments were carried out in a speed-adjustive jar (JTY, Daiyuan, Beijing) with $50 \times 40 \mathrm{~mm}$ flat paddle impellers and a $2 \mathrm{~L}$ beaker at preset rotary speeds and stirring time. Dynamic floc size was measured by Mastersizer and a sample from beaker was circulated through transparent plastic tubing of $5 \mathrm{~mm}$ inner diameter by means of a peristaltic pump at a flow rate of $25 \mathrm{~mL} \mathrm{~min}^{-1}$ and then delivered back to the beaker.

Size measurements were taken every $40 \mathrm{~s}$ for the duration of the jar test. The average size of flocs measured by Mastersizer is in terms of the median equivalent volumetric diameter $D_{[4,3]}$.

Aluminum sulfate $\left(\mathrm{Al}_{2}\left(\mathrm{SO}_{4}\right)_{3} \cdot 18 \mathrm{H}_{2} \mathrm{O}\right.$, analytic reagent) was used as the coagulant and $1.0 \mathrm{M}$ stock alum solutions were prepared with deionized water. The required amounts of coagulant were pipetted into the beaker at the beginning of rapid mixing. Rapid mixing with $250 \mathrm{rpm}$ for $1 \mathrm{~min}$ and slow mixing with $40 \mathrm{rpm}$ for $10 \mathrm{~min}$ were utilized. Furthermore, zeta potential was measured at the $30 \mathrm{~s}$ after adding alum using a zeta potential measurement instrument (Zetasizer 2000, Malvern, UK).

At the preliminary experiments for determining optimal alum dose, 20 min sedimentation was followed by the slow mixing and the residual turbidity of supernatant was measured by Turbidimeter ( $2100 \mathrm{~N}$, Hach, USA). Moreover, $\mathrm{UV}_{254}$ was determined by UV-VIS 8500 spectrophotometer (Tianmei, China) after the samples were filtrated through $0.45 \mu \mathrm{m}$ filters.

\subsection{Relative polarity}

High performance liquid chromatography (HPLC, Alliance 2695, Waters, USA) with UV-VIS detector (2487 Waters, USA) was utilized to separate the dissolved organic matters depending on their relative polarity and C18 packing column (Sunfire, $5 \mu \mathrm{m}$, Waters, USA) was employed as well. The similar method has been reported by Grasso and Weber (1988). Normally, the organic matter with more polarity was less attracted by column packing, resulting in a shorter retention time. Methanol-water mixture with ratio of $80 / 20$ was utilized as the mobile phase. The wavelength of detector was set at $254 \mathrm{~nm}$ and the column temperature was about $20^{\circ} \mathrm{C}$. Water samples of $20 \mu \mathrm{L}$ filtrated by $0.22 \mu \mathrm{m}$ membrane were injected.

\subsection{Fractal dimensions}

The $D_{f}$ was determined by light scattering technology with Mastersizer employment. Scatter light of the particles is proportionally to their size and independent of which part of the particle hit by the beam at a constant angle (Jarvis et al., 2005b). The scattered intensity as a function of the magnitude of the scattering wave vector, $Q$ is measured as 

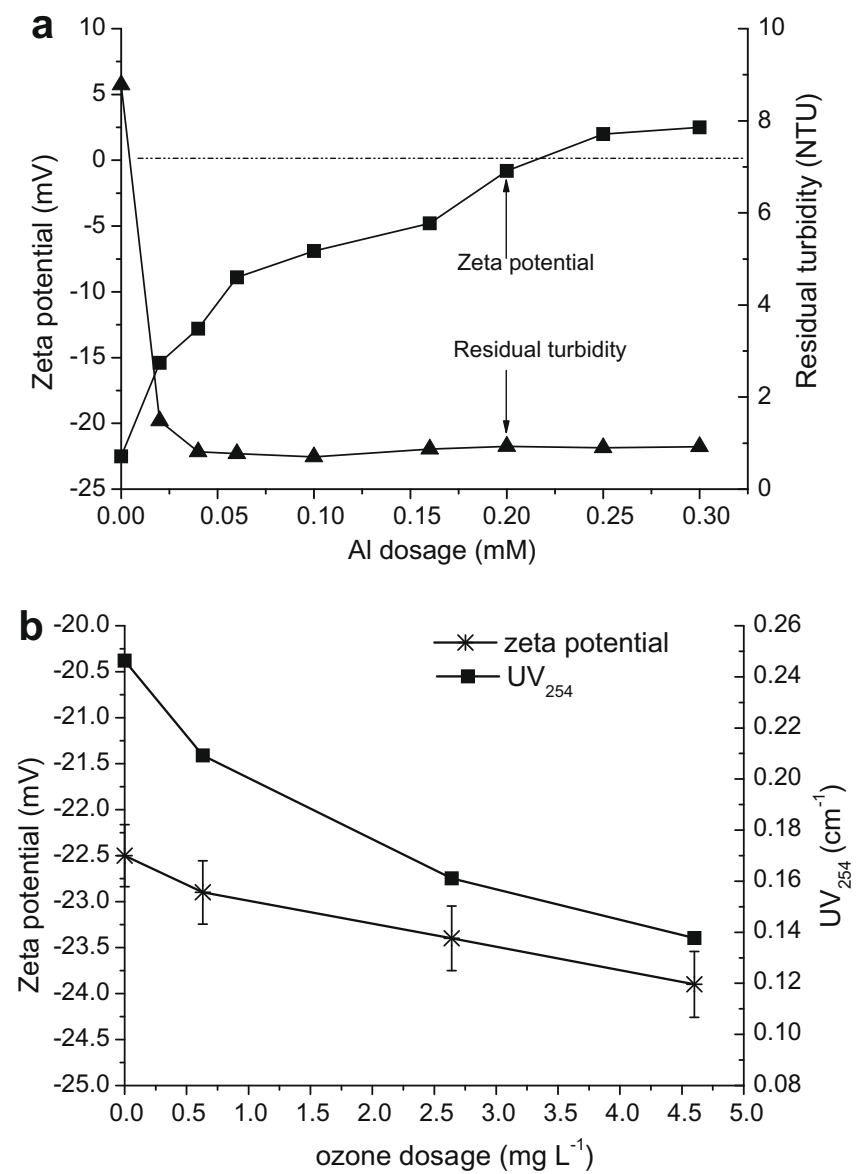

Fig. 1. (a) Variation of zeta potential and residual turbidity on different coagulant doses; (b) effect of different pre-ozone doses on zeta potential and $\mathrm{UV}_{254}$ of suspension.

$Q=\frac{4 \pi n \sin \frac{\theta}{2}}{\lambda}$

where $n, \theta$ and $\lambda$ are the refractive index of the medium, the scattered angle, and the wavelength of radiation in vacuum, respectively (Wu et al., 2002). Fractal flocs have been demonstrated to satisfy the conditions for Rayleigh-Gans-Debye range. Its scattered intensity $I$ is described by the following equation (Biggs et al., 2000).

$I \propto Q^{-D_{f}}$ plot.

Therefore, $D_{f}$ can be determined by the liner slope on a log-log

\subsection{Flocs density}

Free settling testing was employed to measure the settling velocity and the flocs density was determined by modified Stock's equation calculation. At the end of $10 \mathrm{~min}$ slow mixing, about $2 \mathrm{~mL}$ suspension with floc was transferred carefully to a glass settler column by using a wide mouthed pipette. The column size was $30 \mathrm{~mm}$ length, $30 \mathrm{~mm}$ width and $500 \mathrm{~mm}$ height. Additionally, the column was surrounded by a water jacket which was maintained at $20^{\circ} \mathrm{C}$. Movement of flocs was recorded by a Charge-Couple Devices camera (Watec, Japan) coupled with a microscope Len (Computar, Japan). Image analysis software (Mivnt, DaHeng, China) was applied to measure the settling distance at a given time interval for settling velocity determination. Then, the relative effective

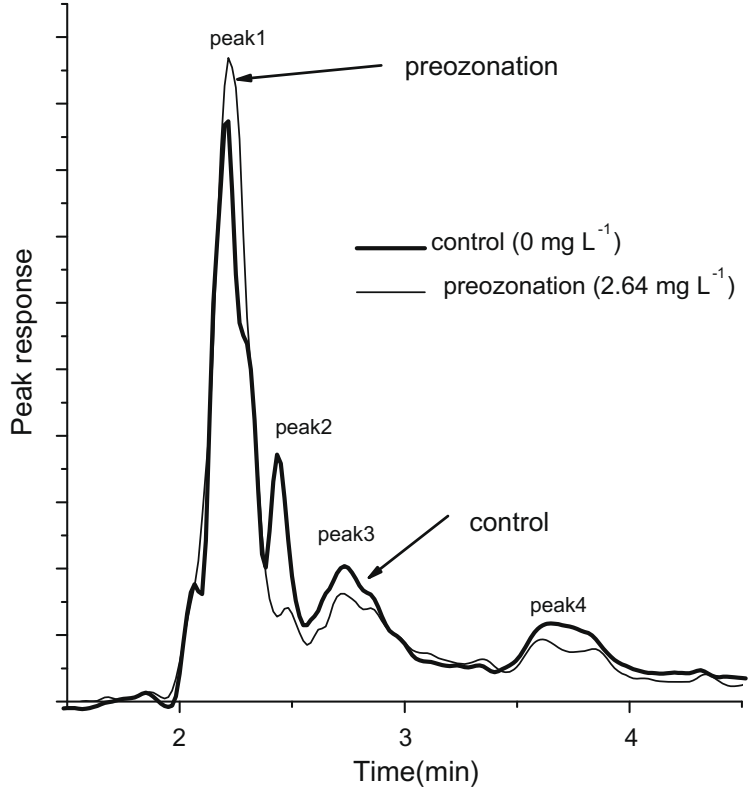

Fig. 2. High performance liquid chromatography curves for the samples with and without preozonation. (control: without preozonation; preozonation: with ozone dose of $2.64 \mathrm{mg} \mathrm{L}^{-1}$ ).

density $\rho_{\mathrm{e}}$ of floc was expressed by the following equation (Glover et al., 2000):

$\rho_{\mathrm{e}}=\left(\rho_{f}-\rho_{L}\right)=\frac{3 \rho_{L} C_{d} v^{2}}{4 d_{S T} g}$

where, $\rho_{L}$ and $\rho_{f}$ is the density of water and floc, respectively; $C_{d}$ is considered as the drag coefficient for equivalent sphere; while, $v$ is the floc settling velocity and $g$ is the acceleration of gravity. Because floc normally shows an ellipsoidal shape, it is necessary to convert the dimensions of the ellipsoidal floc into an "equivalent sphere" diameter, and thus, $d_{S T}$ is the equivalent diameter of sphere that would have the same settling velocity as the ellipse. Both $v$ and $d_{S T}$ can be analyzed by the image software.

\section{Results and discussion}

\subsection{Selection for optimal alum dose}

Fig. 1a showed the variation of residual turbidity and zeta potential as a function of alum dose. The zeta potential of original suspension was about $-22.5 \mathrm{mV}$ and the turbidity was close to 8.8 NTU. When the alum dose was less than $0.10 \mathrm{mM}$, the zeta potential increased remarkably with the alum dose, and the turbidity dramatically decreased. However, as the alum dose was greater than $0.10 \mathrm{mM}$, the zeta potential grew up slightly, but the turbidity remained approximately constant. At an alum dose of $0.20 \mathrm{mM}$, the particle destabilization by charge neutralization occurred, although no obvious turbidity decreasing could be observed. In order to minimize the influence of particles surface charge variation caused by coagulation, the charge neutralization point was employed, and thus, the $0.20 \mathrm{mM}$ alum dose was used at the following research.

\subsection{Impact of preozonation without coagulation}

In order to study the effect of preozonation on the particles, ozonation of the synthetic water should be initially investigated without the addition of alum. Although some researchers consider 


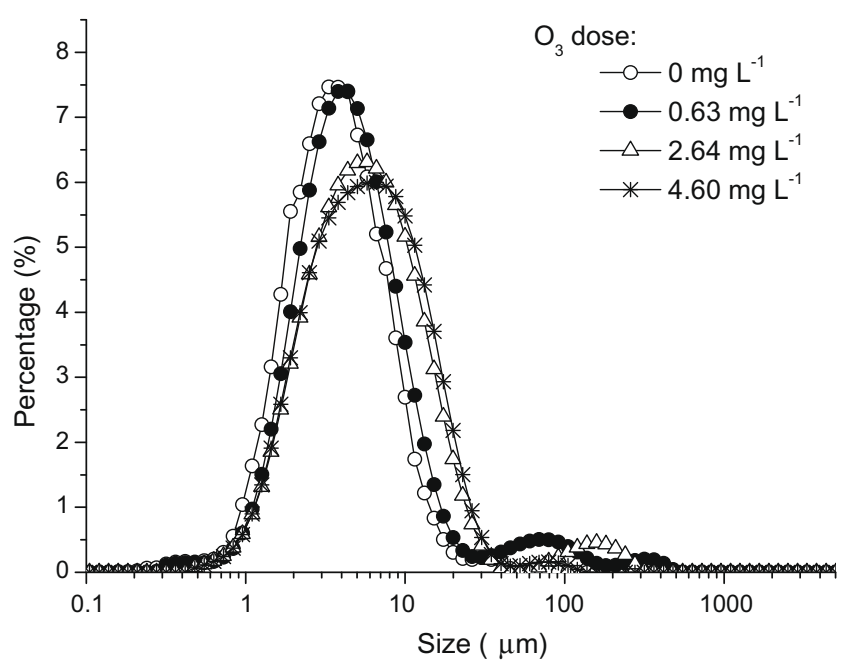

Fig. 3. Particle size distribution under different ozone doses.

that preozonation as an aid in coagulation could be explained as the improvement in reduction of surface charge, Schneider and Tobiason (2000) pointed out that no obvious surface charge reduction could be observed. However, the surface charge played a pivotal role in particle aggregation; therefore, zeta potential had been measured in this research. It can be seen from Fig. 1b that only slight effect on zeta potential was found and the values increased more negative from original -22.5 to $-23.8 \mathrm{mV}$, and thus, there was no aid in particles destabilization could be employed by preozonation due to the increasing repulsion between particle and particle, even only slightly negative charge increase was measured.

It was also evident in Fig. $1 \mathrm{~b}$ that $\mathrm{UV}_{254}$ absorption decreased from 0.25 to $0.14 \mathrm{~cm}^{-1}$ and was inversely proportional to ozone dose, which indicated that preozonation was very efficient in reducing $\mathrm{UV}_{254}$. Similar results had reported by Chang and Singer (1991) and they demonstrated that UV and color was destroyed remarkably without obvious TOC decrease being found after ozonation. Normally, the molecules with unsaturated carbon-carbon bonds, such as double bonds, activated aromatic systems, chained carboxylic acids, were destroyed specifically by oxidizing agents such as ozone, and thus, the ultraviolet absorption at $254 \mathrm{~nm}$ decreased. Additionally, hydrophobic organic matters could be converted to hydrophilic structure (Swietlik, 2004) and organic matter with higher molecular weight oxidized to lower molecular weight material had been demonstrated (Edwards and Benjamin, 1992b). Furthermore, as shown in Fig. 2, totally different polarity of organic matter after ozonation was observed (however, there was no spectacular difference under three different ozone dose, and thus, only curve of $2.64 \mathrm{mg} \mathrm{L}^{-1}$ is shown in Fig. 2 for clarity). As the HPLC method indicated, the relative polarity was estimated as the affinity between organic matters and column packing. Peaks which occurred earlier were representative of organic matters with more polarity. Fig. 2 highlighted the distinction. Four obvious peaks were found within $5 \mathrm{~min}$ of separation time, the response of peak-1 increased when $2.64 \mathrm{mg} \mathrm{L}^{-1}$ was employed. On the contrary, the response of peak-2, 3 and 4 decreased substantially. Therefore, it turned out that the relative polarity of ozonated water increased and this phenomenon was in accordance with the conclusions that relatively polar ozonides, ketones, aldehydes and organic acids were generated by adding ozone (Grasso and Weber, 1988).

The particle size distribution is shown in Fig. 3. For a lower ozone dose of $0.63 \mathrm{mg} \mathrm{L}^{-1}$, the particle size distribution re-

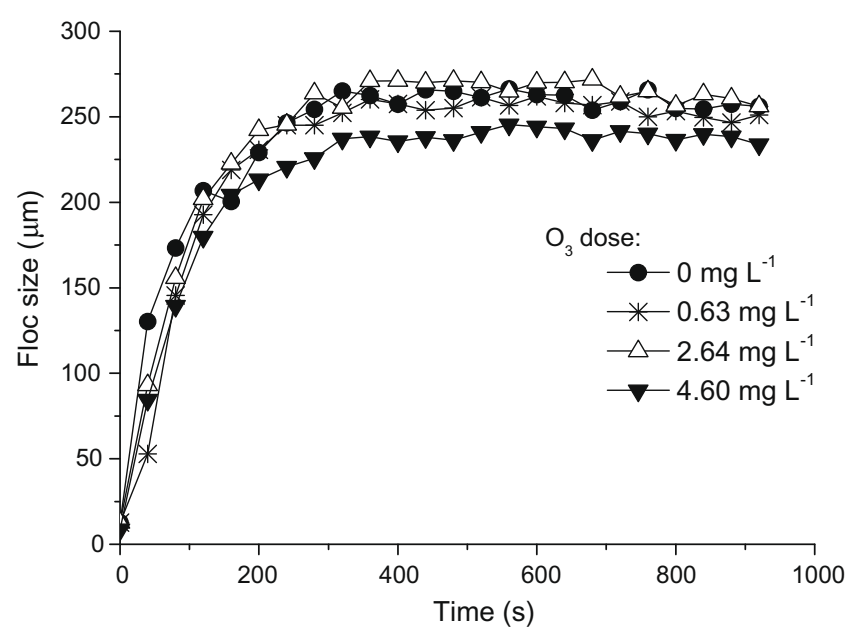

Fig. 4. Kinetics of flocs formation under different ozone doses.

mained approximately constant. Correspondingly, the distribution curves shifted from smaller to larger size as higher ozone dose of 2.64 and $4.60 \mathrm{mg} \mathrm{L}^{-1}$ was introduced. However, there was no apparent distinction between these two higher ozone doses. These results showed that ozone could destabilize and aggregate some smaller particles to form larger ones with an appropriate dose. Within this dose range, the destabilization may be the results of increased adsorption between organic matters with carboxylic acid and particle.

Due to the characteristics of organic matters would be changed by preozonation, the fact that the effectiveness of coagulation might be worsened and that was ascribed to organic matters with lower molecular weight, higher hydrophilic fraction and polarity. Nevertheless, the carboxylic acid content increasing after ozonation may lead to greater metal (such as $\mathrm{Al}$ and $\mathrm{Ca}$ ) association, resulting in enhanced adsorption between metal and organic molecular (Edwards and Benjamin, 1992a; Yan et al., 2007). Due to the complicated and comprehensive organic matters variation, it was difficult to evaluate the effect of preozonation on floc aggregation, and thus, more attention should be paid to the floc properties.

\subsection{Coagulated floc properties with preozonation}

Depending on the dynamic light scattering technology, the kinetics of floc is shown in Fig. 4. At the beginning of $60 \mathrm{~s}$, the floc size increased sharply and reached about $260 \mu \mathrm{m}$ at $300 \mathrm{~s}$, and then it remained approximately constant and the rate of breakage and aggregation of flocs stabilized. No more obvious growth could be observed during the continuous slow mixing after $350 \mathrm{~s}$.

Specifically, there was no apparent floc size distinction after preozonation as relatively low ozone dose of 0.63 and $2.64 \mathrm{mg} \mathrm{L}^{-1}$ employed, meanwhile, the final flocs size range was between 250 and $260 \mu \mathrm{m}$. On the contrary, as the ozone dose increased to $4.60 \mathrm{mg} \mathrm{L}^{-1}$, the flocs size decreased to $230 \mu \mathrm{m}$. Therefore, it could be concluded that the ozone dose, which was less than $0.53 \mathrm{mg}$ $\mathrm{O}_{3} \mathrm{mg}^{-1} \mathrm{C}$, might not influence flocs size dramatically. However, flocs size would decrease, resulting in a lower efficiency of solid-liquid separation when the ozone dose was $0.92 \mathrm{mg} \mathrm{O}_{3} \mathrm{mg}^{-1} \mathrm{C}$. It could be attributed to the breakage of organic matters with large molecular weight. Moreover, a slight decrease of zeta potential (more negative value) (Fig. 1b) was recognized as ozone dose increased, it might enhance repulsion and resistance between flocs and lead to the relatively smaller flocs size. Therefore, there were 

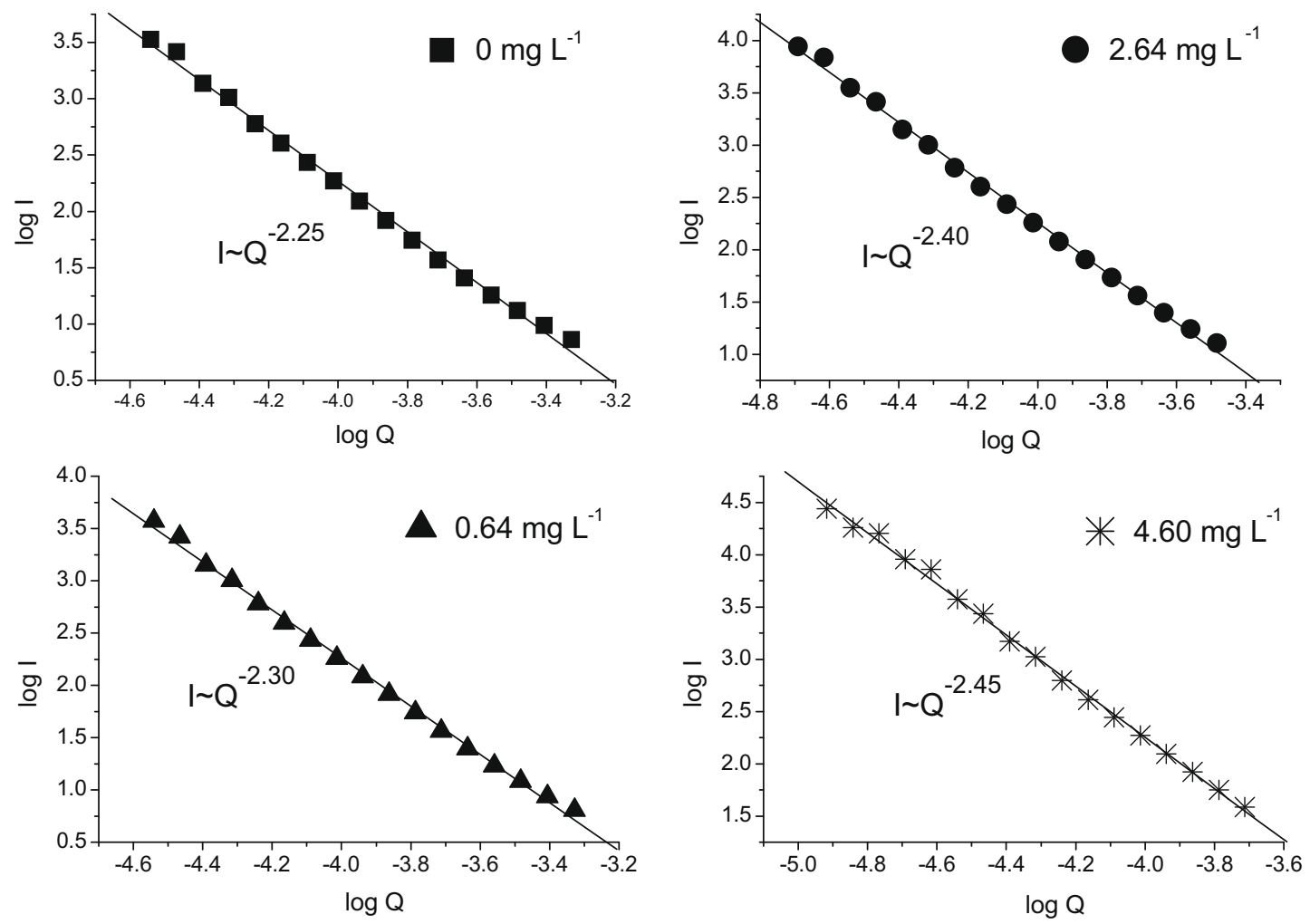

Fig. 5. Mass fractal dimensions determined by light scattering technology under different ozone doses.

optimal ozone doses for formation of a certain floc size. If a higher ozone dose was used, more coagulant dose might be required for obtaining the similar floc size.

Besides the floc size, $D_{f}$ was another significant characteristic of no-spherical flocs. Specifically, densely packed aggregates had a high $D_{f}$, while lower $D_{f}$ resulted from large, highly branched and loosely bound structures. The $\log$-log figure of $I$ and $Q$ is shown in Fig. 5. It was evident that the $D_{f}$ positively increased with the ozone doses. The results showed that the $D_{f}$ of coagulated flocs was affected by the preozonation treatment substantially, which varied considerably at different ozone doses. The $D_{f}$ was 2.25 without preozonation treatment; nevertheless, it increased to 2.45 at the ozone dose of $4.60 \mathrm{mg} \mathrm{L}^{-1}$. It implied that the flocs structure, such as, morphology, porosity, shape, etc., may have been changed. At a low ozone dose, the flocs with low $D_{f}$ showed a more open branch structure; on the other hand, compact and regular flocs with high $D_{f}$ were formed under high ozone dose. As the adsorbed organic matters at particle surface were decomposed at higher ozone dose, the steric hindrance induced by these matters might be decreased, and thus, which would be beneficial to the aggregation of particles. Furthermore, the original aggregates with higher porosity were broken into densely packed aggregates with smaller floc size. Reckhow et al. (1986) demonstrated that ozonation increased the complexation between metal and humate as ascribing to carboxylic acid content improvement, therefore, more dense flocs with high $D_{f}$ were expected to form.

The settling behaviors of flocs showed remarkable difference as the results of size and $D_{f}$ difference under different ozone doses. As shown in Fig. 6 , the $\rho_{\mathrm{e}}$ of flocs was determined by settling column measurement. Generally, flocs with higher $\rho_{\mathrm{e}}$ had higher settling velocity and caused higher effectiveness for solid-liquid separation. The $\rho_{\mathrm{e}}$ was between 400 and $1600 \mathrm{mg} \mathrm{cm}^{-3}$ at a $0.63 \mathrm{mg} \mathrm{L}^{-1}$ ozone dose, higher than the flocs without preozonation. When the ozone dose was $2.64 \mathrm{mg} \mathrm{L}^{-1}$, the highest $\rho_{\mathrm{e}}$ was observed. As mentioned above, flocs formed at $2.64 \mathrm{mg} \mathrm{L}^{-1}$ ozone dose showed that

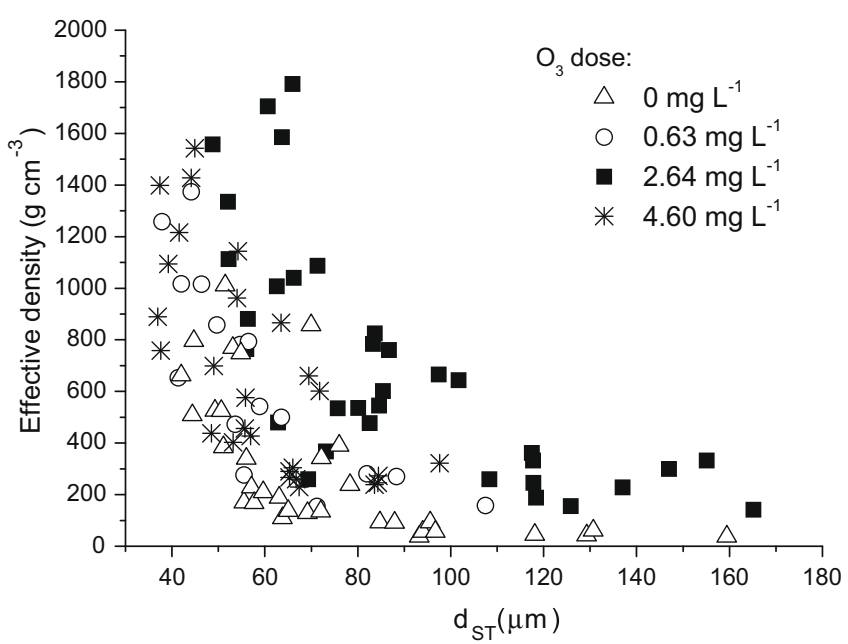

Fig. 6. Effect of ozone dose on the effective density of flocs.

not only higher $D_{f}$, but also larger size, and thus, the highest $\rho_{\mathrm{e}}$ occurred. Correspondingly, at a $4.60 \mathrm{mg} \mathrm{L}^{-1}$ ozone dose, the lower $\rho_{\mathrm{e}}$ was observed than which of $2.64 \mathrm{mg} \mathrm{L}^{-1}$ ozone dose despite the highest $D_{f}$ measured at $4.60 \mathrm{mg} \mathrm{L}^{-1}$, because the smallest floc size, the highest settling drag resistance would be induced.

Therefore, the dose of $2.64 \mathrm{mg} \mathrm{L}^{-1}$ or about $0.53 \mathrm{mg} \mathrm{O}_{3} \mathrm{mg}^{-1} \mathrm{C}$ could be concluded as the optimal preozonation dose depending on the settling behaviors of flocs. At this ozone dose, preozonation functioned as a discernable aid in coagulation.

\section{Conclusions}

The impact of preozonation on the flocs properties was investigated under different ozone doses with three $\mathrm{O}_{3} / \mathrm{TOC}$ ratios. 
Preozonation slightly increased the negative charge of particles and was very efficient in reducing $U V_{254}$, meanwhile, the relative polarity of ozonated water increased. There were optimal ozone dose for floc size formation and floc size decreased as ozone higher than $0.53 \mathrm{mg} \mathrm{O}_{3} \mathrm{mg}^{-1} \mathrm{C}$. Apparently higher fractal dimension was obtained as the ozone doses increased. Especially, the dose of $0.53 \mathrm{mg} \mathrm{O}_{3} \mathrm{mg}^{-1} \mathrm{C}$ can be concluded as the optimal preozonation dose depending on the settling behaviors of flocs. At this ozone dose, preozonation functioned as a discernable aid in coagulation. Summarily, this investigation was expected to improve the understanding of the effects of preozonation on the properties flocs without limitation on surface charge, characteristics of organic matters. Therefore, it may serve as a new way for determination optimal preozonation dose.

\section{Acknowledgment}

The authors thank Dr. Zhe Zhu from East China University of Science and Technology for floc properties measurement. The study was supported by the NSF of China innovative research group fund (No. 50621804) and China national 863 projects (No. 2006AA06Z312).

\section{References}

Amy, G.L., Kuo, C.J., Sierka, R.A., 1988. Ozonation of humic substances: effects on molecular weight distributions of dissolved organic carbon and trihalomethane formation potential. Ozone Sci. Eng. 10, 39-54.

APHA, 1995. Standard Methods for the Examination of Water and Wastewater, 19th ed. American Public Health Association, Washington, DC.

Biggs, S., Habgoog, M., Jameson, G.J., Yan, Y.D., 2000. Aggregate structures formed via a bridging flocculation mechanism. Chem. Eng. J. 80, 13-22.

Bushell, G.C., Yan, Y.D., Woodfield, D., Raper, J., Amal, R., 2002. On techniques for the measurement of the mass fractal dimension of aggregates. Adv. Colloid Interfac. $95,1-50$.

Camel, V., Bermond, A., 1998. The use of ozone and associated oxidation processes in drinking water treatment. Water Res. 32, 3208-3222.

Chakraborti, R.K., Atkinson, J.F., Van Benschoten, J.E., 2002. Characterization of alum floc by image analysis. Environ. Sci. Technol. 34, 3969-3976.

Chakraborti, R.K., Gardenr, K.H., Atkinson, J.F., Van Benschoten, J.E., 2003. Changes in fractal dimension during aggregation. Water Res. 37, 873-883.

Chang, S.D., Singer, P.C., 1991. The impact of ozonation on particle stability and the removal of TOC and THM precursors. J. Am. Water Works Ass. 83 (3), 71-79.

Edwards, M., Benjamin, M.M., 1992a. Effect of preozonation on coagulant-NOM interactions. J. Am. Water Works Ass. 84 (8), 63-72.

Edwards, M., Benjamin, M.M., 1992b. Transformation of NOM by ozone and its effect on iron and aluminum solubility. J. Am. Water Works Ass. 84 (6), 56-66.
Farvardin, M.R., Collins, A.G., 1989. Preozonation as an aid in the coagulation of humic substances - optimum preozonation dose. Water Res. 23, 307-316.

Felix-Filho, J.A., 1985. The effect of aquatic humic substances and ozonation on the stability of particles. Doctoral dissertation, University of North Carolina at Chapel Hill.

Glover, S.M., Yan, Y.D., Jameson, G.J., Biggs, S., 2000. Bridging flocculation studied by light scattering and settling. Chem. Eng. J. 80, 3-12.

Grasso, D., Weber, W.J., 1988. Ozone-induced particle destabilization. J. Am. Water Works Ass. 80 (8), 73-81.

Gregory, J., 1997. The density of particle aggregates. Water Sci. Technol. 36 (4), $1-$ 13.

Jarvis, P., Jefferson, B., Gregory, J., Parsons, S.A., 2005a. A review of floc strength and breakage. Water Res. 39, 3121-3137.

Jarvis, P., Jefferson, B., Parsons, S.A., 2005b. Breakage, regrowth, and fractal nature of natural organic matter flocs. Environ. Sci. Technol. 39, 2307-2314.

Jekel, M.R., 1983. The benefits of ozone treatment prior to flocculation processes. Ozone Sci. Eng., 5-21.

Jiang, Q., Logan, B.E., 1991. Fractal dimensions of aggregates determined from steady-state size distributions. Environ. Sci. Technol. 25, 2031-2038.

Johnson, C.P., Li, X.Y., Logan, B.E., 1996. Settling velocities of fractal aggregates. Environ. Sci. Technol. 30, 1911-1918.

Koen, G., Willy, V., 1997. Image analysis to estimate the settleability and concentration of activated sludge. Water Res. 31, 1126-1134.

Kuhn, W., Sontheimer, H., Steiglitz, L., Maier, D., Kurz, R., 1978. Use of ozone and chlorine in water utilities in Federal Republic of Germany. J. Am. Water Works Ass. 70 (6), 326-331.

Lee, D.G., Bonner, J.S., Garton, L.S., Ernest, A.N.S., Autenrieth, R.L., 2002. Modeling coagulation kinetics incorporating fractal theories: comparison with observed data. Water Res. 36, 1056-1066.

Li, T., Zhu, Z., Wang, D.S., Yao, C.H., Tang, H.X., 2006. Characterization of floc size strength and structure under various coagulation mechanisms. Powder Technol. $168,104-110$.

Liu, H.L., Wang, D.S., Wang, M., Tang, H.X., Yang, M., 2007. Effect of pre-ozonation on coagulation with IPF-PACls: role of coagulant speciation. Colloid. Surface. A 294 $111-116$

Reckhow, D.A., Singer, P.C., Trussell, R.R., 1986. Ozone as a coagulant aid in ozonation: recent advances and research needs. In: AWWA, Annual Conference, Denver.

Schneider, O.D., Tobiason, J.E., 2000. Preozonation effects on coagulation. J. Am Water Works Ass. 92 (10), 74-87.

Swietlik, J.I., 2004. Reactivity of natural organic matter fractions with chlorine dioxide and ozone. Water Res. 38, 547-558

Tang, P., Greenwood, J., Raper, J.A., 2002. A model to describe the settling behavior of fractal aggregates. J. Colloid Interf. Sci. 247, 210-219.

Von Gunten, U., 2003. Ozonation of drinking water: Part I. Oxidation kinetics and product formation. Water Res. 37, 1443-1467.

Waite, T.D., 1999. Measurement and implications of floc structure in water and wastewater treatment. Colloid. Surface. A 151, 27-41.

Wu, R.M., Lee, D.J., Waite, T.D., Guan, J., 2002. Multilevel structure of sludge flocs. J Colloid Interf. Sci. 252, 383-392.

Yan, M.Q., Wang, D.S., Shi, B.Y., Wang, M., Yan, Y., 2007. Effect of pre-ozonation on optimized coagulation of a typical North China source water. Chemosphere 69 1695-1702.

Yukselen, M.A., Gregory, J., 2004. The reversibility of floc breakage. Int. J. Miner Process. 73, 251-259. 